\title{
Results of the open session on "Documentation and monitoring of landslides and debris flows" for mathematical modelling and design of mitigation measures, held at the EGU General Assembly 2009
}

\author{
L. Franzi ${ }^{2}$, D. Giordan ${ }^{1, *}$, M. Arattano ${ }^{1}$, P. Allasia ${ }^{1}$, and M. Arai ${ }^{3}$ \\ ${ }^{1}$ Research National Council, Turin, Italy \\ ${ }^{2}$ Regione Piemonte, Turin, Italy \\ ${ }^{3}$ Meijo University, Civil Engineering, Nagoya, Japan
}

\begin{abstract}
The papers that are here presented and summarised represent the recent scientific contributions of some authors coming from different countries and working in the fields of monitoring, modelling, mapping and design of mitigation measures against mass movements. The authors had the opportunity to present their recent advancements, discuss each other needs and set forth future research requirements during the 2009 EGU General Assembly, so that their scientific contributions can be considered the result of the debates and exchanges that were set among scientists and researchers, either personally or during the review phase since that date. In this resume, the scientific papers of the special issue are divided according to different thematic areas and summarised. The most innovative scientific approaches proposed in the special issue, regarding the monitoring methodologies, simulation techniques and laboratory equipment are described and summarised. The obtained results are very promising to keep on future research at a very satisfactory level.
\end{abstract}

\section{Introduction}

The special issue of the Journal Natural Hazards and Earth System Sciences of the European Geosciences Union, that is titled "Documentation and monitoring of landslides and debris flows" welcomes a limited number of the contributions proposed at the open session on "Documentation and

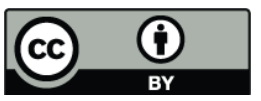

Correspondence to: L. Franzi (luca.franzi@regione.piemonte.it) monitoring of landslides and debris flows for mathematical modelling and design of mitigation measures" that was originally held during the EGU General Assembly 2009 that took place in Wien, Austria on 19-24 April 2009 (http: //meetings.copernicus.org/egu2009/).

The aim of this session was to offer to scientists working in the fields of monitoring, modeling, mapping and design of mitigation measures against mass movements a chance to present their recent advancements, discuss each other needs and set forth future research requirements.

Among the overall 22 presentations 14 were submitted for this special issue and 11 were finally accepted. In the following we will summarize the content and the main results of the published papers.

The papers will be introduced according to a criterion that differs from that adopted to divide the contributions in the different thematic areas during the open session at the General Assembly. In fact their content and the issues that they address allow to follow an ideal thematic path that takes into account the several aspects that need to be dealt with to analyse the complex system of problems posed by the investigation of landslides and debris flows addressed to their hazard mitigation. In particular it is possible to group the different contributions according to an increasing and progressive process of generalization. The first group that we have gathered includes papers dealing with the effective and concrete reality that is met locally on the terrain when the need arises of the collection of field data. Nowadays this latter is then performed through more and more innovative monitoring tools and techniques and is then followed by their storage, organization, retrieval and analysis through modern methodologies and software tools. Therefore we have included in this

Published by Copernicus Publications on behalf of the European Geosciences Union. 
group also a contribution on the implementation of a geodatabase. This first set of contributions is then followed by a group of papers that regard the development, improvement and application of theoretical models that allow a better interpretation, understanding and then prediction of the phenomena that take place at the local level. The authors may also propose an extension of application of their models beyond the boundaries of their local specific characteristics for which they were developed. Finally a group of papers will be presented that propose innovative approaches in the context of risk management, thanks to the birth of new ideas that can be applied to face and manage reality and thanks to new methods, derived from those ideas, to handle it.

This adopted approach in the presentation of the contributions of this special issue, which moves from particular and local aspects to address more general issues, also allows to present an excursus of a portion of the current studies concerning the hazard mitigation of landslides and debris flows. This offers an inside view of the current state of the art of this specific research field. From this latter it should be possible to find inspiration for future, new developments of scientific character.

\section{Field data management and monitoring systems}

The analysis of natural phenomena must be based, necessarily, on databases that may be as consistent and objective as possible. As far as this latter goal is concerned, the continuous advancements and improvements of technology certainly offer an important opportunity. The amount of available data is also increased by the almost constant development of new technologies that allow the collection of new typologies of data, with the employment of innovative monitoring systems. Moreover, nowadays the, storage, cataloguing and handling of the collected data can be performed using GIS software and geodatabase management applications which improve the possibilities to selectively retrieve the information. Many authors are thus involved in these fields of research.

An example of the application of the latter mentioned tool is the technical note "Implementation of a geodatabase of published and unpublished data on the catastrophic Vaiont landslide" (Superchi et al., 2010) that presents a reevaluation of the already existing information on the famous landslide, organized in a ESRI-geodatabase. The 9 October 1963 Vajont landslide represents one of the most important worldwide known gravitational phenomena. Its fame is not only due to the terrible amount of victims and damages that it caused, but also to the chance offered to the scientific community of a better understanding of the mechanics of huge gravitational phenomena. The superposition of a natural process with a large and artificial construction, such as a dam, set a significant study case and a warning for future generations. It also established a natural laboratory in which to investigate failure mechanisms and evolutionary scenarios for the collapse of large rock masses. During the years, this landslide has stimulated a significant amount of research (Giudici and Semenza, 1960; Hendron and Patton, 1985; Muller, 1987; Genevois and Ghirotti, 2005; Semenza, 2010), but a comprehensive explanation of both the triggering phenomena and the complete dynamics is still missing. For this reason, a collection of all the available papers on the subject, particularly those that are not published in electronic form, and their organization in a database represents an important contribution for future researches aimed to a re-evaluation of the occurrences and a more comprehensive understanding of this large instability phenomenon.

As far as the monitoring aspects of the field data collection are concerned, the paper entitled "Microseismic activity analysis for the study of the rupture mechanisms in unstable rock masses" (Amitrano et al., 2010) represents instead an example of a recent experimentation of a microseismic monitoring system applied to the investigation and the stability analysis of an area (the Carrel hut $3829 \mathrm{~m}$ a.s.l., Matterhorn, North Western Alps) that is largely prone to rockfalls. The article describes the structure of the designed monitoring system and the results that have been obtained that are related to the detection of microseismic signals produced by the rock slope deformation. The aim of the project is to investigate the possibility to identify an helpful tool for early warning and preliminary stability assessment that could be applied to a very particular context such as that of the high mountain areas. The alpine areas are particularly sensible to the climate change (Evans and Clague, 1994) and recent studies evidenced a possible correlation between this change and an increase of slope instabilities due to the permafrost degradation (Fisher et al., 2006; Gruber and Haeberli, 2007, Chiarle and Mortara, 2008; Huggel, 2009). This example of investigation of acoustic emissions and microseismic activity represents an interesting test of a monitoring system in a hardly accessible mountain area as the S-W flank of the Matterhorn Peak. The presence of the Carrel hut (a very important logistic point for the climbing activity of the Italian side of the Matterhorn) and the relevant number of rock falls occurred nearby during the recent years created the condition for the implementation of a very complex monitoring system that is still currently working and recording data. Even though the research project is still ongoing, the first results are promising and a noteworthy amount of microseismic data have been collected so far. The analysis of these latter has evidenced a significant correlation between temperature changes and rock slope deformation.

The further two papers belonging to this group both concern the subject of debris flows and the several issues they pose. The paper entitled "“'Description and analysis of the debris flows occurred during 2008 in the Eastern Pyrenees" Portilla et al. (2010), presents the study of some real case debris flow events occurred in 2008 in Spain and at the border of Spain and the Principality of Andorra. The authors claim that research on debris flows has only been performed 
marginally in the Pyrenees and the associated hazard has been mostly neglected. The chief aim of the authors is to deduce information on the susceptibility and the triggering conditions of debris flows occurring in the Pyrenees, starting from the available data regarding the examined debris flows occurred in 2008. The five events are classified by the authors dividing them into two in-channel debris flows and three landslide-triggered debris flows. As far as the triggering conditions based on long-lasting rainfall are concerned, the authors find that data from the Eastern Pyrenees fit the relationships validated for the European Alps. On the other hand, the authors think that new thresholds regarding short duration convective storms must be defined. A 1-D simulation was also performed and described in the paper to find out that the Voellmy fluid rheology fits better than other rheological models the flow behaviour. According to Portilla et al. (2010) the results of their analyses are promising and widen the scope of applicability of the relationships defined in literature so far. More field cases are, however, recommended to refine the presented results.

The last contribution that belongs to this paragraph is titled "Recent changes in rainfall characteristics and their influence on thresholds for debris flow triggering in the Dolomitic area of Cortina d'Ampezzo, north-eastern Italian Alps". In this paper Floris et al. (2010) investigate the variations of climate characteristics in the area of Cortina d'Ampezzo (Dolomites, Eastern Italian Alps), and their possible effects on debris-flow occurrence. The study area is in fact prone to debris-flows, which are normally triggered by summer highintensity and short-duration rainfalls. The authors claim that data gathered through a fixed monitoring system, installed in the Acquabona catchment (Cortina, BL), show that debrisflows are triggered by rainfalls characterized by peak intensities ranging from 4.9 to $17.4 \mathrm{~mm} 10 \mathrm{~min}^{-1}$. High-intensity and short-duration rainfall events, derived from data collected at a specific rain gauge station (located in a locality named Faloria) between 1990 and 2008, show an increase of exceptional rainfall events. In particular the results show that the interarrival time of over-threshold events computed for different threshold values decreased in the last decade. According to Floris et al. (2010) this would suggest that local climatic changes might produce an increase in the frequency of rainfall events that can potentially trigger debris flows.

\section{Shallow landslide and debris flow rheological study and modelling}

Once the modalities for the acquisition and management of data through the use of monitoring systems and GIS have been defined, the next phase in our ideal sequence of steps needed to face the complex problem of dealing with landslides phenomena is represented by the development of numerical models that may allow a better interpretation and understanding of the collected data and then perform a pre- diction of the occurrence and behaviour of the investigated phenomena. The overall goal is the numerical description of the natural process, starting from the single case-study, and its decomposition into a series of rheological models that may allow a better understanding of the investigated phenomenon and the characterization of its behaviour in more general terms.

A more in-depth investigation on the mechanics of debris flows has been described in the paper "An expression for the moving layer in unsteady flows valid for open channels and embankments" (Bianco and Berta, 2010), which analyzes some laboratory tests performed in strongly unsteady flow conditions.

Unsteadiness is a general term employed in the field of mathematical models to describe a particular state of the flow that takes place when uniform flow conditions are no more satisfied. Erosion, deposition and sediment concentration are generally computed applying models that have been developed in steady or uniform conditions. The attempt of the authors is to test the application of the formulas that are proposed in literature for steady flow conditions to describe the mechanics of the water-sediment flows in unsteady conditions. The main assumption of the authors, which is confirmed qualitatively and quantitatively in laboratory experiments, is that the mechanics of water sediment flows may change from steady to unsteady conditions without abrupt variations of the sediment load and of the sediment layer. The formulas proposed by the authors are mathematically derived from those obtained in steady conditions, by simply widening their application field through some correction coefficients calibrated with data derived from their laboratory experiments.

The results essentially agree with those obtained by other authors who investigated immature debris flows and water sediment flows taking place on steep slopes. The Authors suggest that the mechanics of water sediment flows can gradually vary from the conditions of ordinary sediment transport to those of debris flows. Due to the experimental conditions in which the tests have been performed, which were characterised by a strong unsteadiness, the results should be confirmed through a larger number of tests. Bianco and Berta (2010) also underline that some issues may arise on the direct applicability of their proposed formulas to the field, but the first results are certainly encouraging. It is undoubtedly true that the scientific equipments and the methods of measurements employed in laboratory experiments allow sophisticated and precise collection of data that cannot be performed in field conditions. This does not allow a comparison between laboratory and field data that could definitely validate the use of formulas obtained through laboratory tests in real cases. On the other hand, however, practitioners and researchers in many cases do not find representative and quantitative data at all in field conditions, with the exception of some data coming from the few existing instrumented watershed basins. A compromise is thus needed to overcome this 
shortcoming and, accordingly, Bianco and Berta (2010), in their paper, present a proposal.

The scarcity of available field data makes investigation on past debris flows events, aiming to hazard mapping on debris fan, very challenging. The only way to make a back analyses on recent debris flows, unless data from instrumented watershed basins are available in the area, is to simulate the events with a mathematical model and then try to calibrate the output results with the tracks left by the debris flow along the torrent channel or on the debris fan. In this frame the paper titled "Rheological investigation and simulation of a debris flow event in the Fella watershed" (Boniello et al., 2010) shows an attempt to investigate the rheology of debris flows through an indirect method. The major uncertainties that the authors aim to evaluate are represented by the values of the rheological parameters of the water-sediment flow that affected the Fella watershed. The investigation is performed through a field assessment that the authors carry out to verify if the results are coherent with their assumptions. The back analysis approach of the authors is scientifically correct and aims to reproduce, virtually, the mechanics of the occurred phenomena. Some doubts may arise on the applicability of the model proposed by the authors in other sites with similar geomorphological and geographical characteristics, where no recent evidences of debris flows are available to allow a calibration. The hazard assessment, in such situations, still remains a difficult issue to address. In general mathematical models can be usefully applied to test the dependence of the results on the choice of the simulation parameters when field data are available for a comparison and a validation of the simulation results. In this context, mathematical models represent a valuable way to support decision making.

Many models are actually proposed in literature to simulate debris flow triggering, propagation and deposition, ranging from those more theoretically based to those of a more empirical nature. The mathematical and physical architectures of the models can be very different, depending on the effects that are considered in the simulation. The paper "On the application of kinematic models to simulate the diffusive processes of debris flows" (Arattano and Franzi, 2010) focuses on the possibility for simpler mathematical models to still efficiently simulate the mechanics of the debris flows. The authors show that the kinematic model is very easy to be used and applied in practical cases. However the analytical expressions that are derived from the integration of the partial differential equations (p.d.e.) governing the model seem to show a paradox: the very same p.d.e equations simulate different physical behaviours when applied for water floods than for debris flows,. In particular, in water flood simulations, the p.d.e. predict a peak discharge value that remains the same during propagation, while in debris flow simulations the peak discharge value is predicted to decrease downstream. The authors explain the paradox showing that a different choice of the boundary conditions adopted in the integration of the p.d.e. can lead to very different results and, in particular, to different predictions for the behaviour of the wave front. The authors also discuss the ability of kinematic models to simulate the diffusion effects that take place during debris flow propagation. The discussion is based on non-dimensional numbers with specific physical significances that were first introduced by Ponce $(1991,1992)$ in the sixties for the simulation of water floods and applied by the authors to the simulation of debris flows.

The paper "Kinematics of a mass movement constrained by sparse and inhomogeneous data" (Karbon et al., 2011) tackles the problem of establishing a general kinematic model of a landslide with an incomplete documentation of the initial state of the slope, sparse geodetic data collected after the mass movement, very few qualitative geomorphologic observations and a lack of geotechnical parameters. Since experts on hazard mitigation may be frequently confronted with this situation, the authors propose a methodology, based on the use of a double slider block model to fit all observational quantities, to reconstruct the kinematics of the landslide. The use of the FLAC2D code supports the reconstructed kinematics and the Bishop method confirms the estimates of friction angles obtained on the basis of the slider block models.

\section{From the case history to the risk management}

The last group of publications of the special issue gathers the contributions concerning the definition of risk and the delineation of procedures for a more efficient management of this latter. All the research activities on landslides and debris flows have the final goal of contributing to a more efficient and correct management of the risk that could occur through a reduction of the vulnerability of the elements exposed to the risk. Very often this reduction is possible through interventions that directly safeguard the elements at risk. Sometimes, on the contrary, the conditions at the boundary do not allow the construction of permanent active measures and warning procedures must be defined to evacuate the areas at risk in case of emergency. In this latter case, however, it is necessary to draw risk maps and to identify the conditions, usually based on the detection of meteorological parameters, that may lead to a critical situation. Only following this path an application of procedures becomes possible that may minimize the chance that paroxysmal events could cause loss of human lives.

Hsu et al. (2010) propose a modelling procedure for delineation of risk areas affected by debris flows in their country that can improve the accuracy of the hazard zone delineation. In Taiwan this latter is performed through the use of an empirical model adopted in 2003 by the Soil and Water Conservation Bureau. The authors propose a model, named HSPF (Hydrological Simulation Program Fortran), that produces an inflow hydrograph, for the examined watershed, to 
be incorporated into the FLO-2D commercial model: according to them this should enhance the accuracy of the debris flow simulation. The proposed modelling procedure appears capable to predict and delineate the potentially hazardous zones approximately associated with debris flows for a given flood event of a selected design frequency.

Another methodology for hazard assessment has been proposed by Segoni et al. (2009). The authors describe the results obtained in the development of an integrated procedure for the forecasting and consequent warning of distributed shallow landslides to be used for civil purposes.

The approach adopted by Segoni et al. (2009) starts from the analysis of problems and limitations of traditional warning systems that are based only on rainfall observations and propose an innovative methodology that integrates meteorological forecasts, an hydrological model and a geotechnical model to obtain a probabilistic prediction of the location of shallow landslides.

The article describes the proposed methodology and examines the limitations of its application due to the uncertainties of the input data such as the meteorological forecast, the geotechnical parameters and the soil thickness estimated at the basin scale.

The authors present the results obtained from a test site, that evidence the high number of problems that these methodologies pose when they are applied to large areas. However they also underline that this kind of application could be the base for the creation of a shallow landslide warning system. This latter could be also used for the hazard assessment of flash flood events, since the currently employed models are often inadequate.

The last article of the special issue presents a case history: a debris flow event occurred in May 2008 in north western Italy that caused four victims. The paper, titled "Risk management on an alluvial fan: a case study of the 2008 debrisflow event at Villar Pellice (Piedmont, $N$-W Italy)" (Arattano et al., 2010) starts from the analysis of the 28-30 May 2008 event and describes the measures employed for the risk management in the debris flow area. In the Alps a lot of potential dangerous situations exist that are related to the presence of buildings in areas potentially affected by debris-flows, in particular for alluvial fans characterized by a very low frequency of debris flow occurrence. In such cases, it is very difficult to allocate the huge funds required to construct defence works and it is also often very difficult to delocalize the existing houses. Therefore the only solution is to carefully identify the possible scenarios and to plan the possible responses. In order to define a possible solution it is important to take into account the peculiar characteristics of debris flows, such as unpredictability and rapidity of occurrence, high propagation velocity, short duration and destructiveness, and then carefully plan, in particular, all the activities that can be carried out before the occurrence of the events. The aim of the article is to propose possible alternative solutions for the planning of risk management, either from a land planning point of view, or in emergency conditions, that is after a meteorological warning has been issued and then during a possible emergency.

\section{References}

Amitrano, D., Arattano, M., Chiarle, M., Mortara, G., Occhiena, C., Pirulli, M., and Scavia, C.: Microseismic activity analysis for the study of the rupture mechanisms in unstable rock masses, Nat. Hazards Earth Syst. Sci., 10, 831-841, doi:10.5194/nhess10-831-2010, 2010.

Arattano, M., Conte, R., Franzi, L., Giordan, D., Lazzari, A., and Luino, F.: Risk management on an alluvial fan: a case study of the 2008 debris-flow event at Villar Pellice (Piedmont, N-W Italy), Nat. Hazards Earth Syst. Sci., 10, 999-1008, doi:10.5194/nhess-10-999-2010, 2010.

Berta, A. M. and Bianco, G.: An expression for the water-sediment moving layer in unsteady flows valid for open channels and embankments, Nat. Hazards Earth Syst. Sci., 10, 1051-1059, doi:10.5194/nhess-10-1051-2010, 2010.

Boniello, M. A., Calligaris, C., Lapasin, R., and Zini, L.: Rheological investigation and simulation of a debris-flow event in the Fella watershed, Nat. Hazards Earth Syst. Sci., 10, 989-997, doi:10.5194/nhess-10-989-2010, 2010.

Floris, M., D’Alpaos, A., Squarzoni, C., Genevois, R., and Marani, M.: Recent changes in rainfall characteristics and their influence on thresholds for debris flow triggering in the Dolomitic area of Cortina d'Ampezzo, north-eastern Italian Alps, Nat. Hazards Earth Syst. Sci., 10, 571-580, doi:10.5194/nhess-10-571-2010, 2010.

Genevois, R. and Ghirotti, M.: The 1963 Vaiont Landslide - Giornale di Geologia Applicata, I, 41-53, 2005.

Giudici, F. and Semenza, E.: Studio geologico del serbatoio del Vajoint. Unpublished report for S.A.D.E., Part A: 21 pp., text, Part B: 68 photos with discussions, 42 pp., Venezia, Italy, 1960.

Hendron, A. J. and Patton, F. D.: The Vaiont Slide, a Geotechnical Analysis Based on New Geologic Observations of the Failure Surface, I, II, Technical Report GL-85-5, US Army Eng. Waterways Experiment Station, Vicksburg, MS, 1985.

Hsu, S. M., Chiou, L. B., Lin, G. F., Chao, C. H., Wen, H. Y., and $\mathrm{Ku}, \mathrm{C}$. Y.: Applications of simulation technique on debris-flow hazard zone delineation: a case study in Hualien County, Taiwan, Nat. Hazards Earth Syst. Sci., 10, 535-545, doi:10.5194/nhess10-535-2010, 2010.

Karbon, M., Brückl, E., Hegedús, E., and Preh, A.: Kinematics of a Mass Movement Constrained by Sparse and Inhomogeneous Data, Nat. Hazards Earth Syst. Sci., 10, in press, 2011.

Müller, L.: The Vaiont Slide, in: Dam Failures, edited by: Leonards, G. A., Eng. Geol., 24(1-4), 513-523, 1987.

Ponce, V. M.: Kinematic Wave Modelling Where Do We Go From Here?, in: Proceedings of the International Symposium on Hydrology of mountainous areas, Shimla, India, 28-30 May 1992, 485-495, 1992.

Ponce, V. M.: The kinematic wave controversy, J. Hydraul. EngAsce, 117, 4, 511-525, 1991.

Segoni, S., Leoni, L., Benedetti, A. I., Catani, F., Righini, G., Falorni, G., Gabellani, S., Rudari, R., Silvestro, F., and Rebora, N.: Towards a definition of a real-time forecasting network 
for rainfall induced shallow landslides, Nat. Hazards Earth Syst. Sci., 9, 2119-2133, doi:10.5194/nhess-9-2119-2009, 2009.

Semenza, E.: The Story of Vaiont told by the geologist who discorvered the landslide. K-flash Editore, Ferrara, Italy, 205 pp., 2010 .
Superchi, L., Floris, M., Ghirotti, M., Genevois, R., Jaboyedoff, M., and Stead, D.: Technical Note: Implementation of a geodatabase of published and unpublished data on the catastrophic Vaiont landslide, Nat. Hazards Earth Syst. Sci., 10, 865873, doi:10.5194/nhess-10-865-2010, 2010. 